\title{
Falando francamente: o futebol na visão dos escritores, nas Minas Gerais dos anos 1940
}

\author{
Speaking frankly: football in the view of the \\ writers of the 1940s Minas Gerais
}

Marcelino Rodrigues da Silva

Universidade Federal de Minas Gerais (UFMG), Belo Horizonte / Brasil

Doutor em Estudos Literários, UFMG

lino-rodrigues@uol.com.br

\begin{abstract}
Resumo: No segundo semestre de 1949, a Folha de Minas Literária (semanário de "letras, ciências e artes" editado pelo importante jornal Folha de Minas) publicava, geralmente em sua última página, a coluna "Falando francamente", na qual o jornalista Walter Alvares entrevistava personalidades de destaque na vida literária mineira. Num certo momento da entrevista, entre questões sobre os hábitos de escrita e o panorama literário mineiro e nacional, o jornalista lançava repentinamente ao entrevistado a seguinte pergunta: "Gostas de futebol?"; emendando logo em seguida: "Qual o time?" As entrevistas, como um todo, e as respostas a essas perguntas, dadas por nomes como Henriqueta Lisboa, Murilo Rubião, Emílio Moura e João Dornas Filho, oferecem uma oportunidade singular para investigar o modo como o futebol era visto pelos escritores e intelectuais brasileiros daquela época. 0 que se pretende neste trabalho, portanto, é uma análise preliminar desse material, tendo como pano de fundo as reflexões de Milton Pedrosa, em seu famoso ensaio "O futebol na literatura brasileira" (1967), com vistas a uma discussão mais ampla sobre as relações entre o esporte, a cultura e a literatura no Brasil.
\end{abstract}

PalaVRaS-CHAVE: Futebol; Literatura; Imprensa; Escritores; Entrevista.

ABSTRACT: In the second semester of 1949, the Folha de Minas Literária (Literary Minas Journal, a weekly "letters, sciences and arts" supplement published by important newspaper Folha de Minas) published, generally on its last page, the column "Falando francamente" ("Speaking frankly"), in which journalist Walter Alvares would interview important literature personalities in Minas Gerais. At a certain point during the interview, among questions on writing habits and the state and national literary panorama, the journalist would ask the interviewee: "do you like football?", and "which team do you like?" The interviews as a whole, and the answers to these questions by such names as Henriqueta Lisboa, Murilo Rubião, Emílio Moura and João Dornas Filho, offer a singular opportunity to investigate the way football was viewed by Brazilian writers and intellectuals at that time. The intent of this paper is, therefore, to make a preliminary analysis of this material, using as a background the reflections by Milton Pedrosa in his famous essay "O futebol na literatura brasileira" ("Football in Brazilian Literature", 1967), aiming at bringing about a wider discussion about the relationships between sports, culture and literature in Brazil.

KEYwoRDS: Football; Literature; Press; Writers; Interview. 
Quem estuda a relação entre o futebol e a literatura no Brasil certamente conhece o ensaio "O futebol na literatura brasileira”, de Milton Pedrosa, que é a apresentação do livro Gol de Letra, publicado pela editora Gol em 1967, uma referência obrigatória sobre o assunto. Nesse ensaio, Pedrosa faz um diagnóstico que se tornou uma espécie de "versão oficial" sobre a história dessa relação no Brasil. Em linhas gerais, ele afirma que o futebol não recebeu a atenção que merecia dos nossos escritores e que uma das principais causas para isso teria sido o elitismo atávico do nosso meio intelectual, em grande parte oriundo das velhas oligarquias que dominavam o país. É o que se vê, por exemplo, nos seguintes trechos:

Temos então que este esporte, hoje nacional, ainda não foi capaz de interessar os autores brasileiros na medida correspondente ao prestígio e à penetração que alcança nas camadas da população brasileira. Suscitar o problema e estudar as causas do fenômeno, parece-nos tarefa interessante para os que se ocupam com as questões relativas ao desenvolvimento cultural em nosso País, de um modo geral, e, em particular, com o que se refere ao futebol e suas implicações na vida brasileira. ${ }^{1}$

[...] muitas são ainda as pessoas, nas camadas dominantes e nos meios intelectuais, que olham de cima os que lhes falam de futebol. Realmente, o futebol em ascensão, destruindo barreiras que lhe opunha a sociedade, trazia abalo muito violento ao "status". De um certo modo, nessa fase, foi mais incômodo do que empolgante para a "inteligentzia", ainda identificada com os receios e cuidados das mesmas boas famílias a que pertencia e a que estava intimamente ligada por laços afetivos e econômicos. ${ }^{2}$

Para esses herdeiros espirituais do latifúndio e dos senhores de escravos, proeminentes sustentáculos da burguesia, um assunto cuja essência era produto de baixa extração e gozava de má reputação, a seu ver um "caso de polícia", e que ao mesmo tempo ganhava prestígio ao possibilitar a promoção social de pessoas tidas como inferiores, descendentes, talvez diretos, dos antigos escravos, não podia constituir objeto de cogitações de ordem literária ou estética. ${ }^{3}$

Pesquisando a imprensa esportiva mineira da década de 1940, me deparei com um conjunto de documentos que oferecia uma oportunidade interessante de verificar a validade desse diagnóstico, que é amplamente reproduzido por outros textos e autores que estudam o assunto. Daqui para diante, portanto, o que vou fazer é mostrar esses documentos, fazendo deles uma breve e preliminar análise,

\footnotetext{
${ }^{1}$ PEDROSA. O futebol na literatura brasileira, p. 16.

2 PEDROSA. O futebol na literatura brasileira, p. 22.

${ }^{3}$ PEDROSA. O futebol na literatura brasileira, p. 23.
} 
para pensar um pouco sobre essa relação - entre o futebol e a literatura na história cultural brasileira - e, digamos, colocar à prova as afirmações de Milton Pedrosa.

0 conjunto de documentos em questão é uma série de entrevistas com escritores mineiros, publicada em 1949 na Folha de Minas Literária. ${ }^{4}$ Importante observar, aqui, que a Folha de Minas era um jornal muito importante naquela época, reunindo muitos dos principais nomes da intelectualidade local. Essas entrevistas eram feitas pelo jornalista Walter Alvares (que aparentemente era o diretor do suplemento), saíam aos domingos e vinham sob o título "Falando francamente".

No meio da entrevista, que era mais ou menos padronizada e falava de assuntos como os hábitos de escrita e o panorama literário mineiro e nacional, o jornalista perguntava, meio de supetão: “Gostas de futebol? Qual o time?” Entre os entrevistados, encontramos vários nomes importantes da vida literária mineira e nacional, como Henriqueta Lisboa, Murilo Rubião, Emílio Moura e João Dornas Filho.

De uma maneira geral, as entrevistas confirmam o diagnóstico de Milton Pedrosa e mostram uma imagem bem elitista e conservadora dos intelectuais e da atividade literária naquele contexto. É o que se vê, por exemplo, nas respostas de Augusto de Lima Junior, Henriqueta Lisboa e João Dornas Filho:

Tenho horror a casa [sic] selvageria. Minha distração é montar num burrinho e subir e descer serras olhando ao longe os panoramas de nossa Minas. Já fui cavaleiro de concursos. Hoje, os óculos e a idade não comportam tais aventuras. Tenho uma velha vocação agrícola sempre contrariada... Em breve voltarei a ela, comprando uma fazendola perto de Belo Horizonte para onde vou transportar uma parte dos meus livros e nela, entre mugidos de gado, o barulho de um moinho e os encantos da roça, passar o resto dos meus dias.

(Entrevista de Augusto de Lima Junior). ${ }^{5}$

Que assunto esquisito! Falam da necessidade do exercício físico para o aperfeiçoamento da raça, não é verdade? Pois então organizem uma partida de que participem, não apenas 22 jogadores mas, 10.000, os habituais torcedores. Neste caso irei assistir ao espetáculo...

(Entrevista de Henriqueta Lisboa). ${ }^{6}$

Nunca entrei num campo de futebol. Creio que o Nabuco e o Rui também não o fizeram, e nem por isto deixaram de ser o que foram. É lamentável que quando se fecham livrarias e as bibliotecas públicas vegetam precariamente por falta de

\footnotetext{
${ }^{4}$ Os exemplares da Folha de Minas Literária consultados podem ser encontrados na Coleção Linhares - uma formidável coleção de jornais e revistas publicados em Belo Horizonte na primeira metade do século XX, reunida por Joaquim Linhares e hoje sob a guarda da UFMG. Boa parte da coleção está disponível para acesso pela internet (linhares.eci.ufmg.br).

${ }^{5}$ FALANDO francamente. 25 set. 1949 , p. 8.

${ }^{6}$ FALANDO francamente. 09 out. 1949, p. 8.
} 
recursos, se deem rios de dinheiro para um esporte que virou profissão, como qualquer artista de circo de cavalinhos.

(Entrevista de João Dornas Filho).

Na imagem abaixo, podemos ver a página em que foi publicada a entrevista com o Murilo Rubião, em 02 de outubro de 1949. Na foto, o jornalista aparece conversando com o entrevistado, bem aos moldes das entrevistas com jogadores de futebol, que já vinham aparecendo, há algum tempo, nas páginas esportivas dos jornais brasileiros.

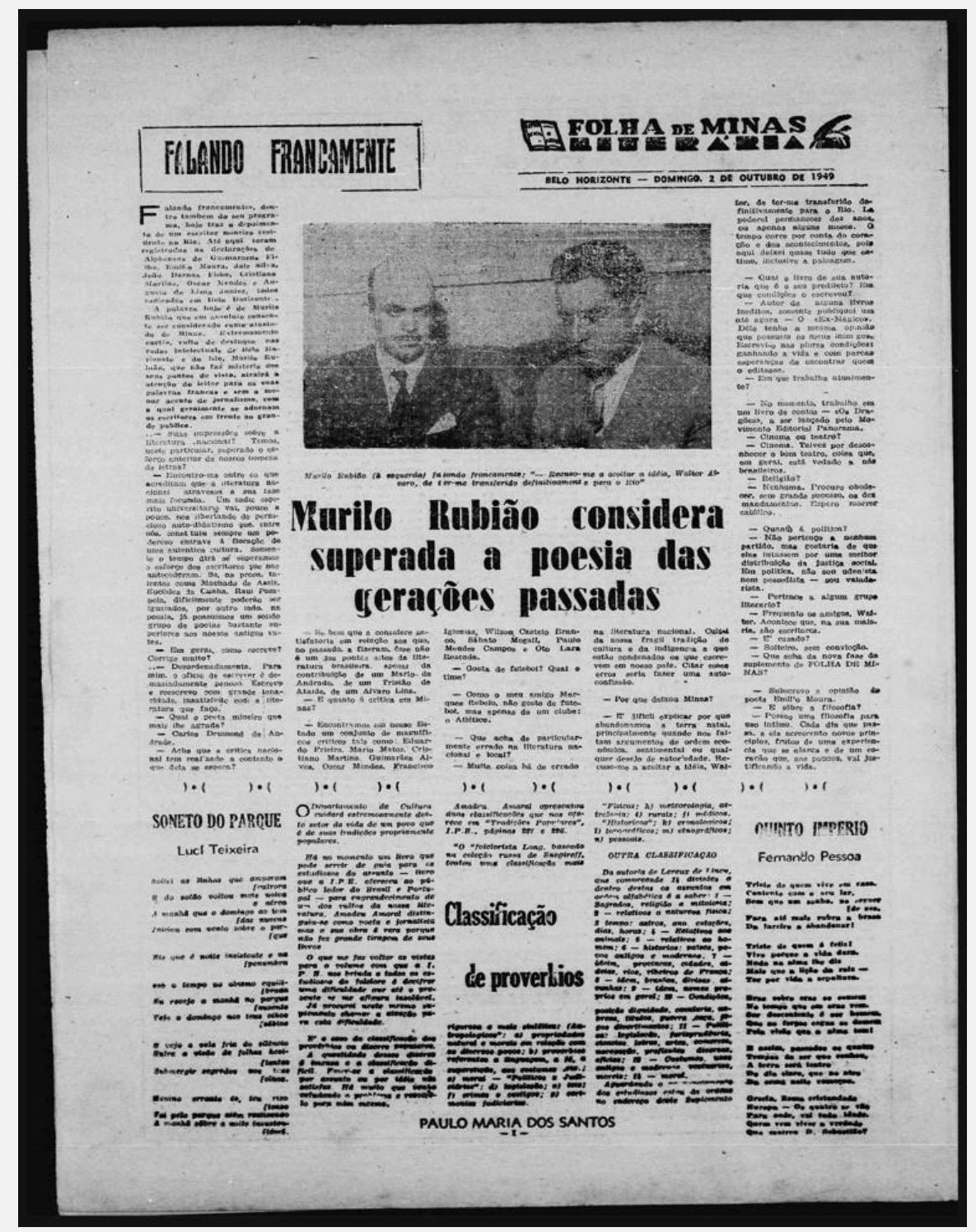

Fig. 01 - Entrevista concedida por Murilo Rubião à coluna "Falando francamente". Folha de Minas Literária, 02 out. 1949, p. 8.

\footnotetext{
${ }^{7}$ FALANDO francamente. 04 set. 1949, p. 8.
} 
Mesmo quando os entrevistados mostram algum apreço pelo futebol, eles parecem ter uma certa nostalgia do éthos amadorista do esporte, do conjunto de valores que o futebol articulava antes de se profissionalizar e se tornar um espetáculo de massas: a ideia do esporte como um símbolo de civilidade, nobreza, urbanidade, respeito às regras, organização etc. É o caso, por exemplo, das respostas do Cristiano Martins e do Oscar Mendes:

Sempre apreciei os espetáculos desportivos que se realizam ao ar livre. E entre estes, o futebol é, ao meu ver, o mais rico em movimentação e, portanto, em certo sentido, em valores estéticos, dadas as suas condições específicas e ao [sic] verdadeiro espírito de organização. 0 clube de minha predileção é o América.

(Entrevista de Cristiano Martins). ${ }^{8}$

Por que essa pergunta de ordem particular no que se refere a determinado jogo e não uma pergunta de ordem geral sobre esportes? E que tem o futebol que ver com a vida intelectual, se o trabalho dele é com os pés? Joguei futebol em menino, como tive espinhas, sarampo e outras coisas passageiras. Fazer disso, porém, uma paixão e até mesmo uma mania é coisa que não se coaduna com meu feitio espiritual. Já passei do período juvenil do entusiasmo esportivo. Isso não quer dizer que se fosse assistir a um jogo de futebol bem jogado e sem "carnificinas" não me entusiasmasse e não torcesse. Sou admirador de tudo quanto é belamente realizado. Mas você sabe bem, seu Walter, como é o futebol entre nós. Virou profissão e deixou de ser jogo - jogatina, com apostas, golpes baixos, subornos, aluguel a quem der mais, etc., etc.

(Entrevista de Oscar Mendes). ${ }^{9}$

Mas, em um número significativo de casos, o que se encontra é não apenas um apreço pelo futebol enquanto espetáculo de massas, mas também uma curiosa adesão ao modo como o esporte vinha sendo fruído pelas classes populares. Sobretudo no que diz respeito às rivalidades esportivas, que foram, em grande parte, as responsáveis pelo progressivo abandono da sociabilidade refinada e elitista dos tempos do amadorismo no futebol. É o que podemos encontrar nas resposta de Alphonsus de Guimaraens Filho, Jair Silva, Emilio Moura e Murilo Rubião:

Gosto. Tenho minhas simpatias pelo Clube Atlético Mineiro.

(Entrevista de Alphonsus de Guimaraes Filho). ${ }^{10}$

Gosto dos jogos realizados sem a interferência dos juízes ingleses. Uma glória da minha vida é ser um dos irmãos do "back" Murilo, do Clube Atlético Mineiro. (Entrevista de Jair Silva). ${ }^{11}$

\footnotetext{
${ }^{8}$ FALANDO francamente. 11 set. 1949 , p. 8.

${ }^{9}$ FALANDO francamente. 18 set. 1949 , p. 8.

${ }^{10}$ FALANDO francamente. 14 ago. 1949, p. 3.

${ }^{11}$ FALANDO francamente. 28 ago. 1949, p. 8.
} 
Gosto muito. Meu maior prazer, nesse terreno, é torcer do lado oposto de meus queridos amigos Mário Matos e Cristiano Martins, que são americanos. Sou torcedor do Atlético desde os tempos de ginásio.

(Entrevista de Emilio Moura). ${ }^{12}$

Como meu amigo Marques Rebelo, não gosto de futebol, mas apenas de um clube: o Atlético.

(Entrevista de Murilo Rubião). ${ }^{13}$

É importante assinalar que o diagnóstico de Milton Pedrosa que serviu de ponto de partida para este trabalho não é tão taxativo e generalizante. Em seu texto, ele aponta uma certa tendência para o surgimento de um interesse novo pelo futebol, justamente porque ele havia se tornado um espetáculo popular. Mais ou menos no início do ensaio, Pedrosa diz que, a partir dos anos 1940, o futebol vinha atraindo uma maior atenção dos escritores brasileiros. E, mais à frente, ele afirma:

As mutações ocorridas no plano mundial na primeira metade do século - as duas grandes guerras e a revolução russa de 1917 - estendendo ao plano nacional a ascensão das massas e a consciência crescente do operariado, e os deslocamentos verificados na sociedade brasileira, que favoreceram 0 surgimento, nas três últimas décadas, de uma intelectualidade mais participante porque mais voltada para as aflições da população desfavorecida, abriram as primeiras brechas na linha de prevenção ante o futebol. ${ }^{14}$

De qualquer maneira, parece-me que o conjunto de documentos apresentado acima mostra um panorama um pouco mais contraditório e multifacetado do que o Milton Pedrosa descreve. A própria presença da pergunta sobre o futebol, no meio de entrevistas com intelectuais, num suplemento literário de um jornal importante e prestigiado, já é sintoma de uma contaminação do mundo intelectual pela popularidade do esporte e pelos conflitos que ele provocava.

Interessante mencionar, a esse respeito, que a Folha de Minas manteve também, mais ou menos na mesma época, a Folha de Minas Esportiva, publicação diária exclusivamente dedicada aos esportes, dirigida por Wilson Figueiredo, poeta e jornalista que teve papel significativo na vida literária mineira, antes de se mudar para o Rio, onde trabalhou por muitos anos no Jornal do Brasil. Em suas páginas, a Folha de Minas Esportiva trazia a coluna "Venenos da torcida", com crônicas

\footnotetext{
${ }^{12}$ FALANDO francamente. 21 ago. 1949, p. 8.

13 FALANDO francamente. 02 out. 1949, p. 8.

14 PEDROSA. O futebol na literatura brasileira, p. 32.
} 
assinadas por Trigo Roxo. Na edição de 26 de setembro de 1949, o cronista responde da seguinte maneira ao depoimento de Augusto de Lima Junior sobre o futebol, publicado no dia anterior e transcrito acima:

No nosso fraco entender, o escritor que assim procede, falha na sua missão, a qual seja a de elevar o nivel intelectual do povo. A arte não foi feita, evidentemente, para uma classe de privilegiados. Ela deve chegar até o povo. Faze-lo sentir o que ela tem de belo e edificante. Enfim elevar o povo até a arte. Ora, um intelectual que deixa de lado as preferências do povo, condenando-as como nocivas, deixa de ser um artista na sua verdadeira concepção, para se tornar um "snob". 15

Como disse acima, o que me propus a fazer neste trabalho é apenas uma análise preliminar desse conjunto de documentos; uma análise que certamente poderia ser mais desenvolvida, em diferentes direções. Eu poderia, por exemplo, ter cotejado as repostas à pergunta sobre o futebol com o restante das entrevistas, em que os escritores opinam sobre outros assuntos. Como a pergunta pela preferência entre teatro e cinema, cujas respostas poderiam ser tomadas como índices de uma atitude mais geral dos entrevistados a respeito das muitas transformações que vinham ocorrendo no mundo artístico e cultural naquele momento, no interior das quais podemos inserir a própria consolidação do futebol como "esporte nacional". Ou poderia ter explorado um pouco as trajetórias intelectuais desses escritores, para buscar relações entre suas opiniões sobre os esportes e suas demais escolhas e posicionamentos em relação à cultura e às questões estéticas e políticas.

Essas possibilidades, por enquanto, não serão exploradas. Mas, para terminar, acho que seria interessante pensar rapidamente em um aspecto dos depoimentos, relativo às circunstâncias enunciativas em que eles foram prestados, ou seja, a situação da "entrevista de escritor". ${ }^{16}$

Nos Estudos Literários contemporâneos, a biografia do escritor tem sido vista de uma forma nova, que inverte o tradicional esquema interpretativo

\footnotetext{
${ }^{15}$ ROXO. Venenos da torcida, 26 set. 1949, p. 4.

${ }^{16} \mathrm{~A}$ abordagem desse aspecto das entrevistas se deve a uma sugestão do historiador Raphael Rajão Ribeiro, feita na ocasião em que apresentei uma versão inicial deste trabalho no VI EPHIS - Encontro de Pesquisa em História, realizado em maio de 2017 na Faculdade de Filosofia e Ciências Humanas da UFMG, integrando a programação do Simpósio Temático História do Esporte e das Práticas Corporais.
} 
segundo o qual a obra reflete, de alguma maneira, a vida de seu autor. Na contramão desse pensamento, e em consonância com a percepção contemporânea da biografia (e das demais representações da realidade) como tributária da ficção, da imaginação construtiva daquele que a escreve, a vida do escritor tem sido vista como uma espécie de romance, construído simultaneamente por ele mesmo (quando posa para fotos, escreve ou fala sobre si mesmo, concede entrevistas...) e por seus biógrafos, fotógrafos, comentadores e entrevistadores. A situação da entrevista, então, seria um "gesto (auto)biográfico", ${ }^{17}$ no qual o escritor encena a si mesmo, protagonizando a história de sua vida e tentando atribuir a ela um sentido global, convergente com o de sua obra.

A pergunta sobre o futebol, lançada de supetão no meio da conversa, força o escritor a reagir diante de um tema que, naquelas circunstâncias, possuía claramente um viés polêmico. Como disse acima, as entrevistas eram mais ou menos padronizadas, e o entrevistado podia certamente saber com antecedência que ela aconteceria. De qualquer modo, sua reação diante da pergunta assume frequentemente o caráter de uma pose, de uma encenação que faz parte da caracterização que ele quer fazer de si mesmo: a evocação do sonho de voltar ao mundo rural, por Augusto de Lima Junior; as referências a Joaquim Nabuco e Rui Barbosa, por João Dornas Filho; e as tiradas meio cômicas e teatrais de Emilio Moura e Murilo Rubião, por exemplo, podem ser interpretadas nesse sentido.

Mas a reação também pode ser de surpresa, dificultando a escolha da pose e deixando escapar algo que, com mais tempo de reflexão, talvez fosse podado e rasurado. Nessas circunstâncias, o diálogo parece adquirir uma certa tensão, muito reveladora das contradições e dos conflitos que atravessavam o campo intelectual brasileiro, na sua relação com as manifestações da cultura popular. Pelo teor das respostas, esse parece ser o caso de Henrique Lisboa e Oscar Mendes, que manifestam um estranhamento com a mistura entre futebol e literatura. Uma mistura que, no entanto, já se fazia bastante evidente, como mostra o intenso intercâmbio de temas, autores e personagens entre as páginas literárias e as páginas esportivas dos jornais brasileiros daquela época.

\footnotetext{
${ }^{17}$ LIMA. A entrevista como gesto (auto)biográfico, p. 32.
} 


\section{REFERÊNCIAS}

FOLHA DE MINAS LITERÁRIA. Belo Horizonte, 1949. [Seleção]. Disponível em: <goo.gl/Hu7g4y>. Acesso em 07 mai. 2017.

LIMA, Rachel Esteves. A entrevista como gesto (auto)biográfico. In: SOUZA, Eneida Maria de; MIRANDA, Wander Melo (Org). Crítica e coleção. Belo Horizonte: Editora UFMG, 2011, p. 32-44.

LINHARES, Joaquim Nabuco. Itinerário da imprensa de Belo Horizonte 1895-1954. Belo Horizonte: Fundação João Pinheiro e Ed. UFMG, 1995.

PEDROSA, Milton. O futebol na literatura brasileira. In: PEDROSA, Milton (Org). Gol de letra: o futebol na literatura brasileira. Rio de Janeiro: Gol, 1967, p. 9-34.

ROXO, Trigo. Venenos da torcida. Folha de Minas Esportiva, Belo Horizonte, 26 set. 1949, p. 4. Disponível em: <goo.gl/Qw77Lmx>. Acesso em: 07 maio 2017. 